\title{
Escrita acadêmica em Português como Língua Adicional: reflexões acerca de biletramento, ensino e avaliação
}

\author{
Ana Laura dos Santos Marques*
}

\section{Resumo}

O objetivo deste trabalho é discutir, por meio de uma análise de textos explicativos de aprendizes hispanofalantes de Português como Língua Adicional (PLA), em contexto de formação universitária, aspectos de suas produções que representam desafios para o trabalho com a escrita acadêmica, tanto em relação ao seu ensino e desenvolvimento paralelo de primeira língua e língua-alvo, quanto em relação à avaliação. Considerando a proximidade entre as duas línguas e os requerimentos dessa aprendizagem, examinamos o conceito de biletramento (HORNBERGER, 2003; 2013), assumindo que usuários de mais de uma língua articulam seu repertório de sistemas linguísticos com uma dupla função: transitar entre uma e outra língua e integrá-las nas diversas situações de produção em que se inserem (CANAGARAJAH, 2011). No caso da escrita acadêmica em duas línguas, a complexidade dessa integração pode ser reconhecida no plano discursivo, com a devida ressalva de que se encontra em um espaço em que as avaliações acontecem desde uma visão monolíngue. A metodologia de análise considera os lineamentos teóricometodológicos da abordagem dos gêneros da Linguística Sistémico-Funcional (MARTIN, 2012; ROSE, 2004; 2007; 2012). Trata-se de um estudo de casos exploratório, com resultados não generalizáveis, que, no entanto, revelam os desafios que a escrita acadêmica representa para os estudos em

\footnotetext{
Universidad de Santiago de Chile (USACH). Doutora em Linguística pela Pontifícia Universidad Católica de Chile (PUC Chile). Docente na USACH. Orcid: http://orcid.org/0000-0002-1587-7492.
} 
PLA em termos de descrição, parâmetros e ensino. Ademais, as análises apontam a necessidade de compreender o processo de biletramento avançado, com um enfoque que articule o trabalho com os gêneros fundamentado em um estudo analítico e descritivo dos textos levados à sala de aula.

Palavras-chave: Abordagem de gêneros. Português como Língua Adicional. Biletramento avançado espanhol-português. Textos explicativos.

\section{Escritura académica en Portugués como Lengua Adicional: reflexiones acerca de biliteracidad, enseñanza y evaluación}

\section{Resumen}

El objetivo de este trabajo es discutir, por medio de un análisis de textos explicativos de aprendientes de portugués como lengua adicional (PLA) en contexto de formación universitaria, aspectos de sus producciones que representan desafíos para el trabajo con la escritura académica tanto en relación con su enseñanza y desarrollo paralelo de primera lengua y lenguameta como en relación con la evaluación. Considerando la cercanía entre las dos lenguas y los requerimientos de su aprendizaje, se examina el concepto de biliteracidad (HORNBERGER, 2003; 2013), asumiendo que usuarios de más de una lengua articulan sus repertorios de sistemas lingüísticos con una doble función: transitar entre una y otra lengua e integrarlas a las diversas situaciones de producción en que se insertan (CANAGARAJAH, 2011). En el caso de la escritura académica en dos lenguas, la complejidad de esta integración puede ser reconocida en el plan discursivo, destacándose que esta se encuentra un espacio donde las evaluaciones ocurren desde una perspectiva monolingüe. La metodología de análisis considera los lineamientos teórico-metodológicos de 
la Lingüística Sistémico Funcional (MARTIN, 2012; ROSE, $2004 ; 2007 ; 2012)$. Se trata de un estudio de casos exploratorio, con resultados no generalizables, que, sin embrago, revelan los desafíos que la escritura académica representa para los estudios en PLA en términos de descripción, parámetros y enseñanza. Además, los análisis apuntan a la necesidad de comprender el proceso de biliteracidad avanzada, con un enfoque que articule el trabajo con los géneros fundamentado en un proceso analítico y descriptivo de los textos llevados al aula.

Palabras-clave: Abordaje de géneros. Portugués como Lengua Adicional. Biliteracidad avanzada español-portugués. Textos explicativos.

Recebido em: 06/03/2021 // Aceito em: 20/04/2021. 


\section{Introdução}

O objetivo do presente artigo é discutir aspectos da escrita acadêmica a partir de uma análise de textos explicativos de aprendizes hispanofalantes de Português como Língua Adicional (PLA) em um contexto universitário de formação de tradutores espanhol-português. Refletimos acerca de como esses aprendizes articulam e utilizam seus conhecimentos discursivos nas duas línguas para produzir seus textos acadêmicos e quais as implicações que esse esforço, na tentativa de responder aos requerimentos da escrita acadêmica, acarreta ao desenvolvimento da língua-alvo, à avaliação de gêneros e à compreensão do termo biletramento avançado. Dadas as conexões entre sua formação em línguas e as especificidades de sua formação em estudos da tradução, contrastamos características discursivas de suas produções e destacamos desafios para o processo de desenvolvimento linguístico que é evidenciado por meio de um gênero textual.

Para desenvolver nossa proposta, ressaltamos como os aprendizes hispanofalantes de PLA lidam com seu processo de biletramento (HORNBERGER, 1989; 2003; 2013) em sua formação universitária. Tal termo se refere a como se dá a inter-relação de dois (ou mais) sistemas para usos particulares socioculturais das línguas do repertório de usuários multilíngues. Em particular, o público hispanofalante aprendiz de PLA compreende que saber a língua portuguesa e saber uma especialidade vinculada com essa língua corresponde a um uso de formas e funções linguísticas por meio de práticas de leitura e de escrita que se distanciam daquelas próprias da comunicação cotidiana. Adicionalmente, esse público também está em processo 
de compreensão do funcionamento e de usos particulares, aplicados à sua área acadêmica, de sua primeira língua, espanhol. Devem lidar, portanto, com práticas institucionais, educacionais e culturais de leitura e escrita, transitando entre uma língua e outra e integrando-as às variadas situações de produção em que se inserem (CANAGARAJAH, 2011).

São reconhecidas duas dentre as funções das práticas de escrita nesse espaço de formação. A primeira delas se relaciona ao fato de que é por meio da escrita que os estudantes são avaliados quanto ao seu domínio linguístico, isto é, quanto ao uso das suas línguas de trabalho, espanhol (sua primeira língua, L1) e português, na produção de gêneros requeridos pelo contexto acadêmico. A segunda função se revela na circunstância de que é por meio da escrita que os estudantes são avaliados quanto à sua aprendizagem dos conteúdos trabalhados em diferentes disciplinas. Ambas as funções destacam o vínculo entre a habilidade de escrita e o processo de formação dos tradutores, ao permitirem a integração de seus conhecimentos para sua participação em práticas de alfabetização acadêmica - ou letramento avançado - de forma mais imediata e, a longo prazo, para usar socialmente os recursos disponíveis em cada um dos sistemas linguísticos de seus domínios - espanhol e português.

Nesse cenário de exigências de uso da escrita em duas línguas próximas, como é o par espanhol e português, comumente encontramos os termos transferências e interferências aplicados às produções de textos dos estudantes. Apesar de reconhecermos a necessidade de que esses aprendizes desenvolvam sua consciência linguística (JÚDICE, 2005) acerca das particularidades léxico-gramaticais entre os dois sistemas, esse não deveria ser considerado o único fator que 
garantiria ou permitiria que tais produções acadêmicas se apresentassem como mais adequadas. É importante considerar que a precisão gramatical deve estar alinhada com o texto e o gênero produzido (SCHLEPPEGRELL, 2002), de forma que estes respondam aos propósitos comunicativos aos quais estão orientados. No caso da escrita acadêmica, a seleção de recursos léxico-gramaticais poderia ser mais bem abordada a partir de uma perspectiva integrada de desenvolvimento da habilidade de escrita (SCHLEPPEGRELL, 2002; SCHLEPPEGRELL, 2012; COLOMBI, 2002).

Analisamos textos explicativos produzidos em disciplinas do curso de graduação em tradução espanhol-português de um grupo de estudantes de PLA. Tais textos estão relacionados com o domínio de um conhecimento específico e a forma como este se apresenta, segundo cada área de especialidade. Por esse motivo, trata-se de um gênero que está em permanente desenvolvimento ao longo de todos os níveis educacionais e exige a seleção adequada de recursos linguísticos associados com determinada área e o conhecimento vinculado a ela (ROSE, 2007).

Baseamos nossas análises no referencial teóricometodológico da Linguística Sistêmico-Funcional (LSF), uma teoria de aprendizagem ou desenvolvimento de linguagem que considera esta última como um sistema sociossemiótico de opções disponíveis orientadas à comunicação, isto é, à criação de significados. Precisamente por enfocar o desenvolvimento da linguagem, provê alternativas de abordagem para os diversos tipos de discurso, tanto em relação com sua aprendizagem quanto em relação com o seu uso, necessários para o desenvolvimento da competência linguística em contextos acadêmicos e profissionais (SCHLEPPEGRELL, 2012, p. 28). 

reflexões acerca de biletramento, ensino e avaliação

Com este trabalho, pretendemos contribuir para a área de PLA, vinculando-a com pesquisas acerca de processos de letramento ebiletramento acadêmico. Ressaltamos a possibilidade de identificar estratégias discursivas comuns entre as línguas que os aprendizes conhecem e são capazes de articular em suas produções textuais, respondendo aos propósitos comunicativos da escrita acadêmica em um marco teórico-metodológico ainda pouco explorado para os estudos em língua portuguesa, em especial, o português como língua adicional.

Este artigo se estrutura nas seguintes seções: Fundamentação teórica, em que expomos alguns antecedentes teóricos que fundamentam nosso trabalho, como a noção de gênero, segundo o referencial da LSF, associada com o contexto de letramento avançado e biletramento e uma breve caracterização dos textos explicativos; Metodologia, contendo o desenho e a descrição dos procedimentos de pesquisa que nos permitiram abordar nossos dados; Análise de dados; e, finalmente, Discussões finais, em que argumentamos acerca de como um estudo de um gênero acadêmico produzido em duas línguas próximas apresenta implicações para a compreensão do processo de letramento e biletramento dos estudantes.

\section{Fundamentação teórica: biletramento espanhol- português e abordagem de gêneros e LSF}

Entre os trabalhos mais conhecidos que destacam a interrelação de dois (ou mais) sistemas para usos particulares socioculturais das línguas do repertório bilíngue, encontramse as pesquisas de Hornberger $(1989 ; 2003 ; 2013)$. Essa autora descreve o processo de biletramento como a prática de alternar 
o uso das línguas em situações de intercâmbios em que a leitura e a escrita possuem um papel central na comunicação. Considerando que o termo letramento faz referência aos usos da leitura e da escrita para que os usuários de uma língua participem de situações comunicativas de uma comunidade letrada, o termo biletramento corresponde a esse mesmo domínio em duas (ou mais) línguas (HORNBERGER, 1989). Seu processo de desenvolvimento está diretamente relacionado com o potencial de entendimento dos gêneros conectados aos contextos sociais de uso. Hornberger $(2003$; 2013) caracteriza o biletramento como dinâmico, contínuo e conectado com variáveis sociolinguísticas, entre as quais estão: a) o grau de conhecimento das línguas envolvidas; b) as funções que os aprendizes atribuem a esse conhecimento; e c) as interferências perceptíveis entre as línguas dos repertórios dos aprendizes. Para a referida autora, há uma interdependência no uso de ambos os sistemas, pois a L1 e a língua-alvo passam a conviver e complementar-se nas diversas instâncias de comunicação, sobretudo através da escrita. Por sua vez, Gentil (2011) ressalta dimensões linguísticas, cognitivas e socioculturais comuns tanto para descrever o processo de letramento quanto para descrever o biletramento.

Aproximações do termo biletramento, para uma melhor compreensão do desenvolvimento das línguas, L1 e língua adicional, complementam percepções e postulados acerca do ensino e da aprendizagem de espanhol e português como línguas adicionais. Desde a década de 1990, pesquisas na área de PLA vêm definindo os contextos de ensino e de aprendizagem para hispanofalantes como particulares. Termos como "compreensibilidade mútua" (ALMEIDA FILHO, 1995; ALONSO REY, 2012), "facilidade aparente" (ALMEIDA 

reflexões acerca de biletramento, ensino e avaliação

FILHO, 1995; 1999), "desenvolvimento da consciência linguística", isto é, como os aprendizes reconheceriam os limites entre os dois idiomas (ALMEIDA FILHO, 1995; 1999; FERNÁNDEZ-RODRÍGUEZ， 1998; FERREIRA， 1998; GRANNIER, 2002; JÚDICE, 2000; 2002), e uma série de trabalhos relacionados com a produção de materiais didáticos e com o emprego de metodologias específicas (JÚDICE, 2002; 2013; MENDES, 2011; ORTIZ-ÁLVAREZ, 2002) tornaram-se familiares para os professores. Apesar de todo esse esforço por compreender as necessidades dos contextos de ensino de PLA, ainda são poucos os trabalhos que se referem a esse par de línguas para propósitos específicos, por exemplo, para a formação profissional que envolva seu uso em contextos universitários ou institucionais, necessariamente vinculados com práticas de leitura e escrita para o ensino e para a aprendizagem.

Os estudos em torno da noção de biletramento representam uma contribuição ao entendimento dos contextos e dos efeitos que as interações sociais mediadas pela leitura e pela escrita possuem. As definições e a caracterização propostas por Hornberger (2013) devem ser relacionadas com análises de gênero que avaliem seus efeitos retóricos e que expliquem o processo de leitura e produção de gêneros. Por esse motivo, nossa proposta com este artigo apresenta uma possibilidade de explorar essa relação entre domínio de línguas e produção de gêneros em um contexto universitário. 


\subsection{0 conceito de gênero na LSF e suas aplicações pedagógicas}

A LSF apresenta uma teoria de aprendizagem ou desenvolvimento da linguagem, considerando esta última como um sistema sociossemiótico de opções disponíveis orientadas à comunicação, isto é, à criação de significados. Sua denominação considera a linguagem como conformada por uma rede de sistemas estratificados inter-relacionados, cada um deles com um conjunto de opções semântico-discursivas, léxico-gramaticais e fonografológicas que se articulam segundo os requerimentos ou funções de usos - contextuais e linguísticos. Trata-se de uma abordagem funcional, dado que as estruturas da língua são explicadas segundo seu significado e as funções comunicativas próprias das situações comunicativas (HALLIDAY, 1998; MARTIN, 2012). Nesse sentido, linguagem e contexto estabelecem uma relação de mútua determinação.

Nessa teoria, o conceito de gênero está articulado com as noções de linguagem e contexto. É entendido como processo social - porque é conformado nas interações com os outros orientado por objetivos - porque responde a algum propósito de comunicação - e está organizado em estágios e fases, porque em geral requer mais de uma fase para significar (MARTIN; ROSE, 2008, p. 54). Sua forma de instanciação (MARTIN, 2012) em textos — isto é, seu potencial para significar — responde às variações que um mesmo gênero pode apresentar, segundo seu contexto de produção e circulação.

O modelo de análise de gêneros proposto pela LSF considera as variáveis de registro - campo, teor e modo - articuladas com suas possibilidades de configurações recorrentes de significados, 

reflexões acerca de biletramento, ensino e avaliação

denominadas metafunções ideacional, interpessoal e textual. As metafunções vinculam contexto e língua, estão presentes de forma concomitante em todo o texto, sendo realizadas nos estratos da linguagem léxico-gramatical e fonografológico. As noções elementares da LSF são representadas por meio de círculos concêntricos, amplamente difundidos em diversas pesquisas da área, que inter-relacionam contexto (gênero e registro) e linguagem estratificados:

\section{Figura 1 - Contexto e linguagem estratificados para a LSF}

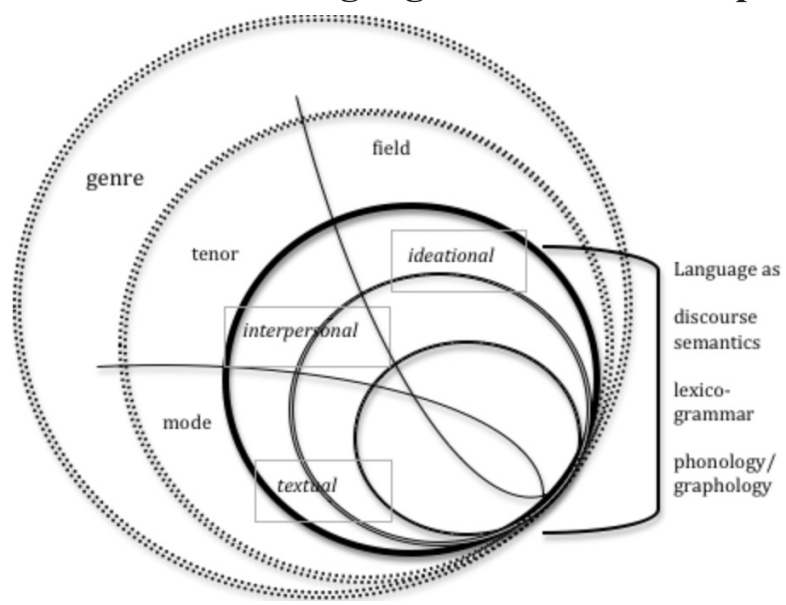

Fonte: Modelo de linguagem em contexto (MARTIN; WHITE, 2005, p. 32).

O desenvolvimento da referida noção de gênero no marco da LSF tem sido aplicado a uma série de projetos de pesquisa-ação em torno da alfabetização e da alfabetização acadêmica (ROSE, 2012, p. 209), impulsionado, sobretudo, por pesquisadores australianos ao longo das últimas três décadas. Desse fato explica-se sua denominação como "Pedagogia baseada em gêneros da Escola de Sidney". Destacam-se, entre as diversas pesquisas publicadas na área de ensino e aprendizagem 
de línguas, tanto primeira quanto língua estrangeira ou segunda, estudos que articulam a descrição de gêneros com o potencial para o desenvolvimento do letramento e de línguas (BYRNES，2009; 2013; SCHLEPPEGRELL，2002；2003; SCHLEPPEGRELL; COLOMBI, 2002; 2012; COLOMBI, 2006; RYSHINA-PANKOVA, 2006; 2015; DE OLIVEIRA, 2014; SIPPERT; ROTTAVA, 2018, entre outros), com o objetivo de incrementar o conhecimento da língua em uso dos aprendizes (ROJAS-GARCÍA, 2016).

Nessa abordagem de gêneros, é por meio do letramento avançado que os aprendizes acedem ao conhecimento acadêmico, ao mesmo tempo em que devem ser capazes de demonstrar sua aprendizagem em gêneros requeridos ao longo de sua formação (ROSE, 2006, p. 1). Assim, o domínio das habilidades de letramento consiste na compreensão e no uso de recursos semióticos organizados na língua-linguagem para a produção das interações sociais, em especial, aquelas específicas dos âmbitos educacionais e institucionais. Exemplificando seu desenvolvimento, Rose (2012) apresenta como se descreveu um conjunto de gêneros, organizados por famílias, que acompanham o desenvolvimento da linguagem e a progressão educacional comum nos contextos institucionais, de acordo com sua definição: processos sociais, seus propósitos comunicativos, seus estágios e fases de organização. Para uma descrição aprofundada dessa abordagem, os trabalhos de Rose e Acevedo (2006), Rose (2007; 2008), Martin e Rose (2008) teorizam como se dá o domínio das habilidades relacionadas com o letramento avançado a partir da compreensão e do uso de recursos semióticos organizados na linguagem para a produção textual nas interações sociais promovidas nos âmbitos escolares/acadêmicos. 

reflexões acerca de biletramento, ensino e avaliação

\subsection{O gênero explicação: uso da língua e reflexão sobre a escrita acadêmica}

No modelo de descrição de gêneros descrito por Rose (2012), os textos explicativos correspondem a práticas de escrita acadêmica por excelência. A habilidade de produzir explicações relaciona-se com o domínio de um conhecimento específico e sua forma convencionalizada para apresentar esse conhecimento. Tanto seus estágios - ou as funções linguísticas que cada etapa do gênero possui - como a gramática - as formas linguísticas selecionadas são consideradas ferramentas adequadas para explorar os padrões de significados nos textos (ROSE, 2007, p. $3)$.

Rose (2007, p. 24-25) refere-se a três padrões descritivos encontrados nas explicações e demonstra como o conjunto de textos classificados nesse gênero possuem relações lógicas entre suas fases que podem variar segundo o fenômeno que enfoca. $\mathrm{O}$ primeiro modelo, explicações sequenciais, articula-se por meio da exposição do fenômeno e logo com uma sequência explicativa em passos articulados. No segundo modelo, explicações fatoriais, observa-se que o fenômeno é derivado de vários fatores ou causas que o geraram. No terceiro modelo, explicações consequenciais, percebe-se o fenômeno como o insumo que gera consequências. Essas descrições revelam que há uma relação entre as formas linguísticas selecionadas e os propósitos de cada explicação. Portanto, a escolha de recursos léxico-gramaticais e sua organização em estruturas simples e complexas da língua apoiam a produção de um gênero acadêmico em que estará plasmada a compreensão do fenômeno que se apresenta.

De acordo com os padrões descritivos das explicações, suas características sintáticas típicas consistem no emprego de 
orações declarativas com verbos no tempo presente. As estruturas coordenadas devem prevalecer nas explicações fatoriais e sequenciais, requerendo, assim, o domínio dos conectores aditivos, adversativos, explicativos e conclusivos. Essas estruturas também impõem ao texto um padrão de complexidade a partir do uso e da articulação de marcadores discursivos que indicam continuidade das descrições necessárias para essas explicações - tais como então, dessa forma, por esse motivo, entre outros. Para os tipos de explicações consequenciais, estão presentes as estruturas subordinadas, por meio do emprego de conectores que expressam o modo, o tempo, a causa e o efeito dos aspectos fundamentais apresentados.

Por fazerem parte do repertório de gêneros acadêmicos, os textos explicativos costumam retratar o funcionamento de um recurso léxico-gramatical conhecido como metáfora gramatical. Descrita por Halliday (1998), esse termo ressalta que o registro acadêmico está funcionalmente orientado à abstração e à objetivação de seu conteúdo (COLOMBI, 2006), condensando a informação para expressar experiências e eventos de um modo "inesperado", por exemplo: ao converter processos, usualmente expressados por meio de verbos, em nomes (substantivos), omitem a atuação de um sujeito e enfatizam, dessa forma, os fatos ou os fenômenos apresentados. Os usos das metáforas gramaticais representam uma escolha (COLOMBI, 2006) e são parte dos recursos disponíveis na construção de orações complexas próprias dos gêneros acadêmicos e/ou científicos. Ao selecioná-las para suas explicações, os estudantes aproximam suas produções ao registro acadêmico.

Os textos explicativos selecionados para a presente pesquisa destacam um dos principais objetivos da escrita 

reflexões acerca de biletramento, ensino e avaliação

acadêmica: ler e escrever, segundo as convenções disciplinares que esses textos requerem (DE OLIVEIRA; LAN, 2014, p. 25). Estão envolvidas as habilidades de leitura e de escrita na línguaalvo e as estratégias discursivas que podem ser aproveitadas no repertório de línguas desses estudantes. Em termos de avaliação, os contextos acadêmicos valoram o conteúdo das explicações, sua validade e sua precisão.

Neste trabalho, o foco está nos aspectos discursivos, nas estratégias de uso e nos recursos léxico-gramaticais selecionados pelos estudantes em suas tentativas de integrar seus conhecimentos para a construção do gênero textual requerido (CANAGARAJAH, 2011). Os procedimentos de coleta de dados e o modelo de análise desenvolvidos encontram-se na seguinte seção.

\section{Metodologia}

Os dados analisados são parte de uma amostragem intencionada de textos explicativos resultantes de uma tarefa de produção escrita realizada por estudantes em duas disciplinas pertencentes ao $2^{\circ}$ e ao $3^{\circ}$ anos de sua grade curricular no curso de graduação em "Lingüística Aplicada a la Traducción da Universidad de Santiago de Chile".

A tarefa dos estudantes consistia em uma atividade de escrita com base na leitura de um artigo acadêmico, em português ou em espanhol, segundo o contexto da disciplina, previsto dentro de uma unidade de trabalho. Após a leitura, realizada de acordo com os prazos indicados por cada professor, e antes das discussões em sala de aula, cada estudante deveria produzir um texto entre 10 e 12 linhas na língua em que a disciplina 
era ministrada - português ou espanhol - contendo uma explicação de um conceito ou fenômeno apresentado no artigo acadêmico lido. A instrução recebida foi: "De acordo com (autor (es/as)) do artigo (título), explique com suas palavras o conceito ou o fenômeno de (conceito/fenômeno)". A consulta ao artigo acadêmico era opcional, ressaltando-se que os estudantes não poderiam recorrer, em suas explicações, nem a citações diretas nem a cópias de trechos do texto fonte.

A partir dessa instrução, obtivemos 20 textos em total, entre os quais selecionamos oito textos, quatro em português e quatro em espanhol, dos mesmos estudantes-autores, que cumpriam com os requisitos especificados na instrução da tarefa. Os autores dos textos selecionados foram contatados para que autorizassem, por meio de cartas de consentimento, a análise de seus textos nesta pesquisa.

É importante destacar que a maioria dos textos dos estudantes apresentava a explicação de um conceito ou fenômeno em menos de 10 linhas, tanto em português como em espanhol. Assim, foi necessário flexibilizar o critério para a seleção dos textos que conformam as análises que apresentamos na seção seguinte.

As análises dos textos em língua portuguesa estão sistematizadas em quadros que destacam o texto (numerado de forma aleatória), o tipo de explicação identificado, segundo a tipologia de Rose (2007), os aspectos retóricos e linguísticos de sua estruturação. A proximidade linguística entre espanhol (a L1 dos estudantes) e português (a língua-alvo) é ressaltada por meio dessas categorias. Os textos selecionados foram produzidos no contexto da disciplina "Produção Escrita em Português I". 

reflexões acerca de biletramento, ensino e avaliação

As análises dos textos em língua espanhola estão reunidas em quadros que mostram as principais características do gênero produzido no contexto da disciplina "Introducción a los estúdios linguísticos", seguindo os mesmos aspectos referidos para os textos em língua portuguesa.

\section{Análises dos dados}

Nos quadros a seguir, os aspectos retóricos e linguísticos analisados correspondem à realização do estrato semânticodiscursivo da linguagem nos estratos léxico-gramatical e grafológico. Do ponto de vista da produção de significados ideacionais, observamos o termo explicado e a presença das metáforas gramaticais. Quanto à produção de significados interpessoais, observamos as modalizações e modulações expressadas pelos estudantes em suas valorações do termo explicado. Finalmente, em termos de significados textuais, observamos os usos dos conectores e suas implicações interoracionais nas explicações desenvolvidas.

\subsection{Análises dos textos em língua portuguesa}

Texto 1

A escrita é uma atividade do ser humano pela qual ele se expressa de maneira gráfica uma mensagem. Por ser inventada, ela pode ser considerada uma tecnologia. Além disso, é importante mencionar que a escrita não é apenas a representação gráfica da oralidade, senão que a ultrapassa e é concebida como uma maneira de pensar, criar e ser. 
Tipo de explicação: Sequencial: o fenômeno + sequência explicativa (caracterização)

Aspectos discursivos:

Uso inadequado de um conectivo - não se pode atribuir a uma interferência do espanhol: pela qual

Apresenta uma caracterização geral: uma atividade do ser humano Articula a caracterização geral com uma específica por meio da introdução de uma cláusula adjetiva: pela qual ele se expressa de maneira gráfica uma mensagem

Modalização (objetividade): ela pode ser considerada uma tecnologia Adição de caracterização: Além disso, Modalização (objetividade): é importante mencionar que a escrita não é apenas a representação gráfica da oralidade

Em termos estruturais, o Texto 1 explica o conceito de escrita sucintamente. A preferência pelo marcador discursivo "senão", ainda que seja também uma possibilidade na língua portuguesa, revela uma estratégia de recorrência à L1, já que a referida forma está mais próxima ao uso acadêmico em espanhol. Com relação ao uso de "pela qual", não podemos confirmar pelo contexto que se trate de uma interferência da L1. As modalizações nas estruturas "pode ser considerada" e "é importante mencionar que a escrita não é apenas a representação gráfica da oralidade" permitem atribuir um carácter de objetividade ao texto, ao mesmo tempo em que marcam a capacidade dos estudantes de avaliar as informações selecionadas para suas produções, aproximando-se ou distanciando-se das afirmações do autor do texto-fonte. (COLOMBI, 2006, p. 158). 


\section{Texto 2}

De acordo com o autor do artigo, em Tradução e Interpretação: uma abordagem teórica e pedagógica, o conceito de esquema pode ser compreendido como o pensamento estruturado no cérebro do indivíduo. Aquele pensamento ou conhecimento é baseado na experiência da pessoa como parte de uma comunidade. Isto é, a vivência de assuntos, situações ou eventos típicos da sua cultura. Os esquemas, também chamados como o conhecimento extralinguístico, vão experimentar alterações em relação ao contexto no qual a pessoa se esteja desenvolvendo.

Tipo de explicação: Sequencial: o fenômeno + sequência explicativa (caracterização)

Aspectos discursivos:

Modalização: pode ser compreendido

Apresenta uma caracterização geral: como o pensamento estruturado no cérebro do indivíduo

Articula a caracterização geral a uma causa: Aquele pensamento ou conhecimento é baseado na experiência da pessoa como parte de uma comunidade

Explicação - uso do conector perifrástico: Isto é Metáfora gramatical: a vivência de assuntos...

No Texto 2, a estrutura do texto explicativo está conformada por verbos no tempo presente do indicativo, de modo geral em orações coordenadas. $\mathrm{O}$ uso do pronome demonstrativo "Aquele" pode ser classificado como um uso da L1 no texto em português. Há dois aspectos que chamam a atenção nessa explicação: a) a presença de uma metáfora gramatical na oração "a vivência de assuntos...", a qual revela um esforço do estudante ao recuperar as informações referidas anteriormente e aproximar-se de uma forma típica da linguagem especializada, condensando a informação, ocultando seu agente e indefinindo o tempo; b) a modalização "pode ser", a qual expressa sua capacidade de avaliar as informações selecionadas a partir do texto-fonte, distanciando-se das afirmações do autor do textofonte (COLOMBI, 2006, p. 158). 
Texto 3

O que é a oralidade?

A oralidade é um dos planos que a fala pode ter ao momento de manifestarse e caracteriza-se principalmente por na maioria dos casos ter um caráter espontâneo (os falantes não sempre sabem como vai ser o ato comunicativo e também não se preparam para ele), econômico (há uma tentativa de dizer a mensagem de maneira mais breve e concisa) e pela sua função comunicativa/dialógica (exprime uma mensagem com o objetivo de provocar uma reação no interlocutor).

Se bem anteriormente fazia-se a diferenciação com a escrita tomando os argumentos do espaço e o tempo, a verdade é que estes não permitem diferenciar bem os fenómenos da fala escrita e a fala oral. Na oralidade, os interlocutores podem estar ou não estar presentes no mesmo espaço (numa entrevista em vivo entre o noticiário e o entrevistado no lugar dos fatos, por exemplo) e também é possível que não estejam no mesmo tempo (um discurso político gravado e retransmitido na televisão, por exemplo).

Tipo de explicação: Sequencial: o fenômeno + sequência explicativa (caracterização)

Aspectos discursivos:

Definições: entre parênteses

Uso da L1: $\underline{\text { Se bem }}$

Articula a caracterização geral com uma descrição mais específica: $\underline{\text { Se }}$ bem anteriormente fazia-se a diferenciação com a escrita tomando os argumentos do espaço e o tempo, a verdade é que estes não permitem diferenciar bem os fenómenos da fala escrita e a fala oral.

Nominalização: fazia-se a diferenciação com a escrita

Exemplificação: sempre entre parênteses

Na oralidade, os interlocutores podem estar ou não estar presentes no mesmo espaço (numa entrevista em vivo entre o noticiário e o entrevistado no lugar dos fatos, por exemplo) e também é possível que não estejam no mesmo tempo (um discurso político gravado e retransmitido na televisão, por exemplo).

No Texto 3, a explicação caracteriza-se pela sequência explicativa do termo oralidade. A primeira parte do texto está constituída por verbos no tempo presente do indicativo, em orações coordenadas aditivas. Os parênteses são usados nas exemplificações e definições. A segunda parte é introduzida 

reflexões acerca de biletramento, ensino e avaliação

pelo uso do conector "se bem", o qual corresponde a um uso da L1 no texto em português. A intenção de introduzir uma oração concessiva resulta produtiva em termos de efeitos retóricos da segunda parte da oração com relação à primeira, porém, a forma escolhida para isso em português não foi a adequada. A nominalização identificada corresponde a uma seleção pouco comum em português no contexto destacado.

\title{
Texto 4
}

\begin{abstract}
A oralidade
A oralidade é um dos principais meios que temos para comunicar-nos com os outros de forma rápida e efetiva. A fala apresenta três marcas fundamentais que a caracterizam. A primeira é que as conversações entre duas ou mais pessoas não são planejadas, quer dizer que é espontânea e que não precisa de uma estrutura muito organizada, sempre que os interlocutores possam entender-se. A segunda é a presença de marcas de formulação ou reformulação, ou seja, o tempo que tem o falante durante a fala lhe permite criar, organizar ou repensar o que vai dizer nesse momento. A terceira é a mais importante é como e quando o falante vai comunicar-se de forma oral, para isso é necessário ter em conta os seguintes conceptos: a atitude da pessoa que se reflete na entoação, o ritmo, as pausas, a ênfase e o tom de voz. Outro ponto a destacar é a relação entre os sujeitos que participam no ato comunicativo, o tempo e o espaço em que eles se encontram, pois isto vai ser determinante para entender algumas questões que contextualizam a oralidade.
\end{abstract}

Tipo de explicação: Sequencial: o fenômeno + sequência explicativa (caracterização) 
Aspectos discursivos:

Apresenta uma caracterização geral: é um dos principais meios que temos para comunicar-nos com os outros de forma rápida e efetiva Não usa o infinitivo conjugado em português: comunicar-nos Articula a caracterização geral com uma descrição mais específica: A fala apresenta três marcas fundamentais que a caracterizam. A primeira [...]. A segunda $[\ldots]$ A terceira $e ́$ a mais importante [...].

Marcadores discursivos: A primeira - A segunda - A terceira - Outro ponto a destacar

O Texto 4 caracteriza-se pela sequência explicativa do termo oralidade. A primeira parte está constituída por verbos no tempo presente do indicativo. $\mathrm{O}$ estudante estrutura seu texto em torno das marcas de fala, conforme identificado no texto-fonte. Para isso, utiliza adequadamente marcadores discursivos que indicam suas características principais, em uma classificação segundo sua ordem de importância. Como um aspecto de mescla entre a L1 e o português, destaca-se o uso da forma verbal "comunicarnos", em lugar do infinitivo conjugado em português.

\subsection{Análises dos textos em língua espanhola}

Os textos em língua espanhola, etiquetados com letras de A a D, explicam os conceitos "proceso" e "procedimiento" e foram produzidos pelos mesmos autores dos textos analisados em português. Como podemos apreciar nos quadros com a sistematização das análises, o tipo predominante de explicações é sequencial. Não há uma grande variação na estrutura das explicações, as quais apresentam um verbo no presente (ser, corresponder), orações coordenadas e exemplificações. Os textos A e B possuem uma estrutura mais próxima a uma resposta 
a uma pergunta do que um texto explicativo, como os que apresentamos na seção anterior. Os textos C e D diferenciam-se dos demais textos dessa amostra devido aos recursos linguísticos empregados, a um maior número de estruturas complexas e à presença de estratégias de modalização e da metáfora gramatical. Por esse motivo, decidimos apresentar, no presente artigo, somente as análises dos textos B e D.

\section{Texto B}

Proceso es una etapa continua y flexible que permite un fin determinado. Por ejemplo: el proceso de leer un libro, sin importar el tiempo, el lugar o la forma en que lo leas, lo importante es que el proceso finalice y logre la meta, que es terminar de leer el libro.

Procedimiento: son una serie de pasos determinados, discontinuos y poco flexibles, con el objetivo de realizar una tarea. Por ejemplo: seguir una receta de comida paso a paso, aunque no siempre de manera continua, ya que este puede tener pausas y luego reanudar el procedimiento, para terminar el plato.

Tipo de explicación: Secuencial: el fenómeno + secuencia explicativa

Aspectos discursivos: Define los dos términos

Presenta una caracterización general

Ejemplifica: desde el concepto a un hecho concreto

Usa verbos en presente: ser

No hay marcadores discursivos

No hay una conclusión o cierre del texto. Tras las dos explicaciones y las dos ejemplificaciones, se concluye la explicación. 
Texto D

Proceso: acción mediante la cual se llevan a cabo las etapas previamente visualizadas y planificadas. Es la manera en que accionamos el procedimiento. En esta realización no es necesario que se cumpla al pie de la letra lo estipulado anteriormente, debido a esto, en aquellos casos se debe adoptar o modificar el procedimiento al curso de la actividad.

Procedimiento: son las directrices y metodologías que se usan para desarrollar un proceso ideal. Es un mapa de ruta donde se planifican paso a paso los objetivos a completar en el proceso.

Las planificaciones que hacen los profesores practicantes son un buen ejemplo de esto, ya que ellos deben crear un esquema de cada clase, que involucra diversos elementos didácticos y pedagógicos, pero una vez en clase, la actividad puede alterarse dramáticamente de acuerdo a diversos factores tales como: la disposición de los alumnos, el clima, el estado de ánimo del profesor, etc., frente a lo cual, éste deberá adaptar su planificación.

Tipo de explicación: Secuencial: el fenómeno + secuencia explicativa

Define los dos términos

Presenta una caracterización general

Usa verbos en presente: son

Emplea un mayor número de formas lingüísticas en las oraciones, formando estructuras complejas (acción mediante la cual se llevan a cabo...)

Metáfora gramatical: En esta realización no es necesario Modalización: puede alterarse; no es necesario que, se debe adoptar... Presenta una relación entre los dos conceptos definidos. Para esto, establece relaciones adjetivas en las oraciones, con pronombres relativos como conectores; oración explicativa (ya que...), causal (debido a esto) No hay una conclusión para el texto. El cierre se da con la articulación de los ejemplos ofrecidos a los dos conceptos explicados anteriormente.

\subsection{Sistematização dos dados: textos explicativos em português e textos explicativos em espanhol}

De acordo com as análises dos textos explicativos em português e em espanhol, observamos a presença dos seguintes recursos e etapas de conformação: 
- A especificação do conceito que será explicado: quase sempre ocorre por meio de classificação e descrição.

- Um dos modelos de explicação, de acordo com Rose (2007): tipo sequencial.

- Em termos linguísticos, as explicações são produzidas em orações com verbos no presente do indicativo, sendo possível identificar de forma recorrente: ser, corresponder, consistir. A caracterização do fenômeno se dá com a presença dos conectores aditivos e relativos.

- O emprego de estratégias de modalização para a expressão de significados interpessoais e de metáforas gramaticais, entre os ideacionais, demonstra uma aproximação dessas explicações ao registro acadêmico. Revela ainda o processo de desenvolvimento das línguas e de seus repertórios, à medida que há um emprego de estruturas mais típicas do discurso acadêmico e um distanciamento de formas mais próximas à oralidade.

Quanto à constituição do gênero textual "explicação", eram esperadas as referências ao autor, artigo e contexto. Tais referências estão relacionadas com a manutenção da coerência e da coesão nesses textos, além de fazerem parte do registro acadêmico e científico. Tal como ressaltam De Oliveira e Lan (2014, p. 24), nos contextos de desenvolvimento do letramento avançado, promove-se uma recontextualização do discurso da ciência, o qual se caracteriza pela "densidade informacional, tecnicidade, abstração e autoria". Ainda que tenham sido produzidos em contexto de sala de aula e como tarefa de escrita, essas explicações deveriam apresentar e organizar a informação relacionada em construções que reconhecem o texto fonte, situando de onde provêm as informações explicadas. Entre os textos analisados, encontramos somente alguns dados bibliográficos no Texto 2 . 
A modo de justificação desse fato, podemos atribuir a ausência de dados bibliográficos à instrução recebida pelos estudantes para desenvolverem a tarefa. Nessa instrução, não se solicitava a produção de um gênero textual de forma explícita, mas, sim, a escrita de uma explicação de um conceito ou fenômeno, segundo a leitura realizada. Portanto, as explicações recebidas consistem em uma resposta ao que foi solicitado. Além disso, os estudantes utilizaram estratégias retóricas já consolidadas em uma das línguas de seus repertórios para atender e responder à instrução recebida - sabendo que esta teria como único leitor o professor da disciplina (quem, além de transmitir a instrução da tarefa, já contava com as informações de autoria do texto fonte) — com maior ou menor grau de precisão que o texto explicativo requeria no contexto de escrita acadêmica.

\section{Discussões finais}

A partir das análises realizadas nos textos explicativos de aprendizes hispanofalantes de PLA em contexto universitário, nossos dados permitem algumas reflexões acerca da produção de textos explicativos. Quanto aos textos produzidos, esses são o resultado de tarefas de escrita de disciplinas ministradas em português e em espanhol. Estiveram diretamente relacionados com a leitura de um artigo acadêmico nas duas línguas. Deveriam seguir as instruções de produção dadas pelo professor de cada disciplina, embora não tenhamos informação acerca do tipo de abordagem de gênero e da escrita em sala de aula. Em termos de avaliação de competências linguísticas dos estudantes que contribuíram com seus textos para este trabalho, é evidente que compreendem a instrução dada e se centram em conceitualizar 
um termo de sua área de conhecimento, tal como mostramos em nossas análises. Desenvolvem seu esquema de explicação em sequências, precisando a informação como consequência da leitura e da compreensão que tiveram do termo.

A estrutura dos textos explicativos requer um uso de recursos léxico-gramaticais comuns nas duas línguas envolvidas: verbos no tempo presente do indicativo, orações coordenadas, emprego de conectores relativos e orações adjetivas. Nesse aspecto, a aparente facilidade da tarefa não deve ser desprezada ao se tratar do trabalho com um gênero acadêmico. Vale destacar algumas perguntas acerca desse tipo de prática de escrita, bastante comum nas atividades de formação universitária: Quais os propósitos para esse tipo de tarefa? A escrita medirá conhecimentos acerca do conteúdo ou somente se avalia o uso da língua? É possível avaliar de forma conjunta conteúdo e uso dos recursos linguísticos? As análises dessas produções ampliam tais reflexões, visto que os textos explicativos analisados mostram como os estudantes fixam-se no contexto de solicitação da tarefa e dos propósitos da interação, a saber, a resposta ao professor sobre determinado conceito ou fenômeno.

Atendendo ao objetivo desta pesquisa, discutir, por meio de uma análise de textos explicativos de aprendizes hispanofalantes de português como língua adicional (PLA) em contexto de formação universitária, aspectos de suas produções que representam desafios para o trabalho com a escrita acadêmica, tanto em relação ao seu ensino e desenvolvimento paralelo de primeira língua e língua-alvo, quanto em relação à avaliação, podemos afirmar que a complexidade para abordar os referidos textos é alta. A proposta de análise que apresentamos, ainda que de forma incipiente, aponta para a importância de que 
professores de PLA descrevam e conheçam a estrutura dos textos que solicitam a seus estudantes, explicitem suas características linguísticas e desenvolvam um trabalho com os gêneros por meio do qual avaliarão o conteúdo e o desenvolvimento linguístico dos aprendizes.

Para futuros estudos que considerem a noção de biletramento, é importante que se contemple realizar análises textuais com a compreensão do intercâmbio de estratégias que os estudantes promovem entre as línguas de seus repertórios, porém, tendo em vista que a explicitação de recursos linguísticos em uso, isto é, em gêneros como propósitos sociais, organizados em etapas, deve estar vinculada com o potencial epistêmico da escrita (CARLINO, 2013): a escrita motiva reflexão sobre o próprio conhecimento e, ao mesmo tempo, estrutura esse conhecimento ao destiná-lo a um interlocutor. Em termos de aprendizagem de línguas com fins específicos, como é o caso de estudantes de tradução português-espanhol, aprender a língua e aprender sobre a língua constituem tarefas fundamentais em suas atividades universitárias. As semelhanças entre português e espanhol são evidentes, o grau de complexidade dos gêneros com os quais lidarão será variável, mas, sobretudo, reconhecemos que é essencial uma proposta de enfoque do PLA que abarque a compreensão e a produção de textos na e para a formação universitária.

\section{Referências}

ACEVEDO, C.; ROSE, D. Reading (and writing) to learn in the middle years. Primary English Teaching Association, [s. l.], n. 157, p. 73-84, 2007. 

reflexões acerca de biletramento, ensino e avaliação

ALMEIDA FILHO, José Carlos Paes. O professor de língua estrangeira em formação. Campinas: Pontes, 1999.

ALMEIDA FILHO, José Carlos Paes. Uma metodologia específica para o ensino de línguas próximas? In: ALMEIDA FILHO, José Carlos Paes de. (org.). Português para estrangeiros interface com o espanhol. Campinas: Pontes, 1995. p. 13-21.

ALONSO REY, María Rocío. El mito de la facilidad en el estudio del proceso de enseñanza y aprendizaje de PLE-HE. Estudios Portugueses, [s. l.], n. 4, p. 11-38, 2005.

ALONSO REY, María Rocío. Portugués para hispanohablantes: aspectos teóricos y prácticos de un área emergente de investigación. 2012. Disponível em: <https://dialnet.unirioja.es/ servlet/articulo? codigo=4680391>. Acesso em: abr. 2020.

BYRNES, H. Emergent L2 German writing ability in a curricular context: a longitudinal study of grammatical metaphor. Linguistics and Education, [s. l.], n. 20, p. 50-66, 2009.

BYRNES, H. Advanced language proficiency. In: GASS, S. M.; MACKEY, A. The Routledge Handbook of Second Language Acquisition. London / New York: Routledge, p. 2013. p. 506521.

CANAGARAJAH, S. Codemeshing in academic writing: identifying teachable strategies of translanguaging. The Modern Language Journal, [s. l.], n. 95, p. 401-416, 2011.

CARLINO, P. Alfabetización académica diez años después, Revista Mexicana de Investigación Educativa, [s. l.], v. 18, n. 57, p. 355-381, 2013.

COLOMBI, M. C. Gramatical metaphor: academic language development in Latino students in Spanish. In: BYRNES, H. Advanced language learning: the contribution of Halliday and Vygotsky. London: Continuum, 2006. p. 147-162.

COLOMBI, M. C.; Joseph HARRINGTON. Advanced Biliteracy Development in Spanish as a Heritage Language. 
In: BEAUDRIE, S.; FAIRCLOUGH, M. (eds.): Spanish as a Heritage Language in the US. Washington: Georgetown University Press, 2012. p. 241-258.

DE OLIVEIRA, L.; LAN, Shu-Wen. Writing science in an upper elementary classroom: a genre-based approach to teaching English language learners. Journal of Second Language Writing, [s. l.], n. 25. p. 23-39, 2014.

FERNÁNDEZ-RODRÍGUEZ, María. Como aprender a aprender e melhorar a produção escrita em Português. In: JÚDICE, Norimar; PINTO, P. F. (org.). Para acabar de vez com Tordesilhas. Lisboa: Colibri, 1998. p. 65-80.

FERREIRA, Itacira A. Português/espanhol - fronteiras linguísticas que devem ser delimitadas. In: ALMEIDA FILHO, José Carlos Paes de. (org.). Português para estrangeiros: interface com o espanhol. Campinas: Pontes, 1998. p. 34-48.

GENTIL, G. A biliteracy agenda for genre research. Journal of Second Language Writing, [s. l.], n. 20, p. 6-23, 2011.

GRANNIER, Daniele. Uma proposta heterodoxa para o ensino de Português a falantes de espanhol. In: JÚDICE, Norimar. Português para estrangeiros: perspectivas de quem ensina. Niterói: Intertexto, 2002. p. 57-80.

HALLIDAY, M. A. K. Things and relations. In: MARTIN, J. R.; VEER, R. Reading science: critical and functional perspectives on discourses of science. London/New York: Routledge, 1998. p. $185-235$.

HORNBERGER, Nancy. Continua of biliteracy. Review of Educational Research, [s. l.], v. 59, n. 3, p. 271-296, 1989.

HORNBERGER, N. H. Biteracy continua. In: HAWKINS, M. R. (Ed.). Framing languages and literacies: socially situated views and perspectives. New York, NY: Routledge, 2013. p. 149-167. 

reflexões acerca de biletramento, ensino e avaliação

HORNBERGER, N. H. (ed.). Continua of biliteracy: an ecological framework for educational policy, research, and practice in multi-lingual settings. Clevedon, UK: Multilingual Matters. 2003.

JÚDICE, Norimar. Módulos didáticos para grupos específicos de aprendizes estrangeiros de português do Brasil: uma perspectiva e uma proposta. In: PEREIRA, A.L.; GOTTHEIM, L. (org.). Materiais didáticos para o ensino de língua estrangeira - Processos de criação e contexto de uso. Campinas: Ed. Mercado de Letras, 2013. p. 147-184.

JÚDICE, Norimar. Português/Língua estrangeira: leitura, produção e avaliação de textos. Niterói: Intertexto, 2000.

JÚDICE, Norimar. Português para estrangeiros: perspectivas de quem ensina. Niterói: Intertexto, 2002.

JÚDICE, Norimar. Seleção e abordagem de fotografias, cartuns e quadrinhos no ensino da língua e da cultura do Brasil para estrangeiros. In: JÚDICE, N. Ensino da Língua e da Cultura do Brasil para Estrangeiros. Niterói: Intertexto, 2005. p.31-51. MARTIN, Jim. Systemic functional linguistics. In: HYLAND, Ken; PALTRIDGE, Brian. (ed.). The continuum companion to discourse analysis. London/New York: Continuum, 2011. p. 101-119.

MARTIN, J. R. One of three traditions: genre, functional linguistics and the Sydney School. In: ARTEMEVA, N.; FREEDMAN, A. (Ed.). Genre around the globe: beyond the three traditions. Edmond, AB: Trafford, 2012. p. 31-77.

MARTIN, Jim; WHITE, Peter. The language of evaluation: appraisal in English. Londres/Nueva York: Palgrave/Macmillan, 2005.

MARTIN, J. R.; ROSE, D. Getting going with genre. In: MARTIN, J. R.; ROSE, D. Genre relations: mapping culture. London: Equinox, 2008. p. 1-48. 
MENDES, Edleise. Diálogos interculturais: ensino e formação em português língua estrangeira. Campinas: Pontes, 2011.

ORTIZ-ÁLVAREZ, Maria Luisa. Os fraseologismos como expressão cultural: aspectos de seu ensino em PLE. In: CUNHA, Maria Jandyra C.; SANTOS, Percilia. Tópicos em Português Língua Estrangeira. Brasília: UnB, 2002. p. 157-174.

ROJAS-GARCÍA, I. Aportes de la lingüística sistémicofuncional para la enseñanza de la lectura y la escritura en la educación superior. Educ. Educ., v. 19, n. 2, p. 185-204, 2016.

ROSE, D. Genre in the Sydney school. In: GEE, J. P.; HANDFORD, M. (ed.). The Routledge handbook of discourse analysis. London: Routledge, 2012. p. 209-225.

ROSE, D. Literacy and equality in the classroom. In: SIMPSON, Alyson. (ed.). Future directions in Literacy: international conversations. Sydney: Sydney University Press, 2006.

ROSE, D. Reading genre: a new wave of analysis. Linguistics and the Human Sciences, [s. l.], v. 2, n. 1, p. 1-27, 2007.

ROSE, D. Sequencing and pacing of hidden curriculum: how indigenous learners are left out of the chain. In: MULLER, J.; MORAIS, A.; DAVIES, B. Reading Bernstein, research Bernstein. London: Routledge Falmer, 2004. p. 91-107.

ROSE, D. Writing as linguistic mastery. In: MYHILL, D. et al. (ed.). Handbook of writing development. London: Sage, 2008. p. 151-166.

ROSE, D.; ACEVEDO, C. Closing the gap and accelerating learning in the middle years of schooling. Australian Journal of Language and Literacy, [s. l.], v. 14, n. 2, p. 32-47, 2006.

RYSHINA-PANKOVA, M. A meaning-based approach to the study of complexity in L2 writting: the case of grammatical metaphor. Journal of Second Language Writting, [s. l.], v. 29, p. 51-63, 2015. 

reflexões acerca de biletramento, ensino e avaliação

SCHLEPPEGRELL, Mary J. Challenges of the science register for ESL students: errors and meaning-making. In: SCHLEPPEGRELL, Mary J.; COLOMBI, M. Cecilia. (coord.). Developing advanced literacy in first and second languages. New York: Routledge, 2002. p. 119-142.

SCHLEPPEGRELL, M. J. Systemic functional linguistics. In: GEE, J. P.; HANDFORD, M. (ed.). The Routledge Handbook of discourse analysis. London: Routledge, 2012. p. 21-34.

SCHLEPPEGRELL, Mary J. The language of schooling: a functional linguistic perspective. New Jersey: Lawrence Erlbaum, 2004.

SCHLEPPEGRELL, M. J. The linguistics features of advanced language use: the grammar of exposition. In: BYRNES, H. Advanced language learning: the contribution of Halliday and Vygotsky. London: Continuum, 2006. p. 134-146.

SCHLEPPEGRELL, Mary J.; COLOMBI, M. Cecilia. Developing advanced literacy in first and second languages. New York: Routledge, 2002.

SIPPERT, Luciane; ROTTAVA, Lúcia. Estudo semânticodiscursivo da referência textual sob a perspectiva da Linguística Sistêmico-Funcional, 2018. Disponível em: $<$ https://www.seer. ufrgs.br/organon/article/view/81493>. Acesso em: abr. 2020. 